\title{
INMIGRANTES MUSULMANES EN CATALUÑA ${ }^{1}$
}

\author{
JORDI GARRETA BOCHACA \\ Universidad de Lleida
}

PALABRAS CLAVE ADICIONALES

Inmigración, Religión, Práctica Religiosa, Islam, Mezquitas, Transmisión del Islam.
ADDITIONAL KEYWORDS

Immigration, Religion, Religious Practices, Islam, Mosques, Islamic Transmission.

RESUMEN. Los flujos migratorios de los últimos treinta años, en general, y concretamente, han comportado el incremento de la heterogeneidad cultural y también religiosa en España y en Cataluña. $\mathrm{Al}$ analizar la diversidad cultural que aportan los inmigrantes no hemos querido olvidar la cuestión religiosa. Por este motivo, observando el creciente número de musulmanes, la investigación realizada, y este artículo en particular, analiza la presencia del Islam en Cataluña a partir de entrevistas a imanes. De esta forma presentamos las mezquitas existentes, la dinámica seguida en su creación, las motivaciones que tienen, las dificultades que encuentran y los retos de futuro que creen que deben afrontar ellos y la sociedad catalana.

\section{BREVE APROXIMACIÓN AL ISLAM EN ESPAÑA}

En España existe un Islam autóctono, pero que poco tiene que ver con las organizaciones de musulmanes inmigrantes (Losada, 1995 y Moreras, 1996). Los musulmanes extranjeros no tenían organización religiosa en España hasta la publicación de la Ley 44/1967 del 28 de junio; su presencia consistía en centros culturales poco definidos. A partir de esta fecha se inscriben las primeras asocia-

'Este estudio se ha realizado con una beca de la Fundación Jaume Bofill.

\section{Revista Internacional de Sociología (RIS)}

Tercera Época, nº 25, Enero-Abril, 2000, pp. 151-176. 
ciones islámicas. La Asociación Musulmana de España, con sede en Madrid, inició la negociación con el Estado español para que fueran reconocidos y aplicados los derechos que otorgaba la ley de libertad religiosa. En el seno de esta asociación, durante el año 1990, aparecen ocho comunidades musulmanas repartidas por la geografía española (Valencia, Granada, Madrid, Zaragoza, Asturias, Terrassa y Alicante) que formarán en 1991 la Unión de Comunidades de España (López y Olmo, 1995). Desde ese momento las comunidades islámicas se extienden por gran parte del territorio español, principalmente por el tercio sur de la península y el norte de África (Tatary, 1995)². Estas asociaciones, como también ha afirmado Leveau (1994), actúan como intermediarios en la negociación del proceso de integración: las de ámbito nacional respecto a la situación oficial del Islam, mientras que las de nivel local resuelven problemas más cotidianos, aunque de alto valor simbólico para la comunidad. Para Losada Campos (1995) y López y Olmo (1995) los años 80 representarían el periodo de crecimiento del Islam en España, potenciado por la revolución iraní, que jugará un papel importante en la identidad colectiva, y por la promulgación de la ley de Extranjería en 1985 con el incremento inmediato del reagrupamiento familiar.

«Cuando lo provisorio se hace durable, el espacio cultural cerrado y desubicado se ve progresivamente obligado a transformarse en un espacio cultural en la sociedad de acogida. Esta extrapolación no es unilateral; la sociedad autóctona requiere cambiar la mirada frente a una población que no está de paso. Los inmigrantes se han organizado creando redes de solidaridad. Instalan tiendas en donde se vende carne lícita para el consumo. La vida se estructura en torno a la mezquita. Esto se explica por el carácter del Islam, que regula no sólo la práctica religiosa y moral, sino también las relaciones sociales" (Losada, 1995: 194).

Un musulmán con residencia temporal puede realizar sus rezos y prácticas en cualquier lugar, pero si se instala es necesario que se organice como grupo. La sedentarización en España de musulmanes ha comportado que en la actualidad existan cuatro mezquitas (sin contar las existentes en Ceuta y Melilla) y más de quinientos oratorios. Las mezquitas y los oratorios ${ }^{3}$ tienen múltiples funciones:

\footnotetext{
${ }^{2}$ Para conocer la dinámica seguida en algunos países europeos, como Francia, Bélgica, Alemania y Gran Bretaña, pueden consultarse: F. Dasseto (1990a; 1990b; 1990c), R. Leveau y G. Kepel (1988), R. Kastoryano (1984) y G. Kepel (1991a, 1991b, 1995a, 1995b).

${ }^{3}$ Los oratorios generalmente los financian los mismos fieles, y no es habitual la intervención de países de origen en su gerencia, a pesar de que, con aportaciones puntuales, intenten conseguir el dominio político e ideológico del colectivo (Losada, 1995). Pero siguiendo a Rozenberg (1996), que reproduce palabras del padre Emilio Galindo, el Islam está politizado a nivel de
} 
son un espacio de socialización para todo el colectivo musulmán y también el eje estructurador de la comunidad, organizando el grupo y consolidando la presencia del Islam en la zona que abarca (Rozenberg, 1996).

Como Moreras (1996 y 1999) observa, los ritmos en la apertura y consolidación de las comunidades islámicas varían en función de la fase de asentamiento en que se encuentran. Este proceso está condicionado por otros factores, como la reacción de los vecinos, el apoyo de las instituciones locales o la intervención de otros promotores no comunitarios. Concretamente, fijándose en lo que sucede en la ciudad de Barcelona y las comarcas colindantes, Moreras establece cinco etapas en la evolución de la presencia del Islam: la década de los sesenta -caracterizada por la ausencia de espacios comunitarios y la práctica religiosa no visible-; de 1970 a 1983 - años en que se crean los primeros centros aunque exista lo que llama precariedad comunitaria—; de 1984 a 1987 — primera fase de dispersión, es decir, creación de espacios comunitarios en algunas localidades de las comarcas de Barcelona-; de 1988 a 1992 — segunda fase de dispersión, caracterizada por la visibilización y estabilización comunitaria-, y a partir de 1992 - fase de progresiva regularización de los espacios de culto.

Pero esta presencia, además de por los diferentes ritmos de apertura y consolidación, tampoco es homogénea en cuanto a expresión pública. Según Losada (1995) se pueden distinguir cuatro formas de expresión del Islam en España, que van desde el laicismo al islamismo militante:

1. Practicantes instalados. Son principalmente inmigrantes de género masculino con una edad aproximada entre treinta y treinta y cinco años para los cuales el retorno al Islam coincide con la decisión de asentarse con su familia en origen para evitar la absorción de sus hijos.

2. Islam de segunda generación. Se trata de jóvenes que no rechazan su cultura ni su religión, pero que la adaptan a la nueva situación debilitando su práctica a manifestaciones externas (Ramadán y fiestas) y olvidando la práctica cotidiana: Su identidad está aún por definir y depende en parte de la estrategia familiar.

3. Musulmanes sociológicos. Tienen una referencia al Islam más cultural que de culto.

4. Militantes islamistas. Tienen una visión negativa de la emigración fuera de su país por el miedo a la asimilación y la pérdida de la identidad religiosa.

asociacionismo. El mismo especialista cree que hay una distancia entre los musulmanes europeos por la posesión entre los primeros de un sentimiento de regreso a la patria perdida ( $\mathrm{Al}$ Andalus) y por la creencia de que España tiene una deuda histórica con ellos. 
Esta diversidad de situaciones las pudimos observar en un estudio que realizamos en las provincias de Lleida y Huesca ${ }^{4}$, que complementaba una encuesta a inmigrantes extracomunitarios (en función de la población existente en estas provincias una gran parte de ellos eran musulmanes africanos) y entrevistas en profundidad a musulmanes e imanes. Nuestro interés se focalizó en el grado de seguimiento de la práctica religiosa, ya que el hecho de que practiquen o no, no tiene por qué ser un reflejo de lo que hacían en su país de origen. El estudio detectaba una serie de cambios provocados por la emigración, y en muchos casos se trataba de cierta modificación de las prácticas religiosas que realizaban en España. Mayoritariamente, poco más del $60 \%$ no habían alterado sus prácticas religiosas y sólo una tercera parte confesaba haber modificado algunas prácticas (los restantes no quisieron responder a la cuestión planteada). Los cambios más importantes suponían: no seguir rezando las cinco veces diarias $(35,4 \%)$, consumir alcohol $(31,3 \%)$, no celebrar el Ramadán $(23,6 \%)$, consumir carne de cerdo u otros alimentos prohibidos $(16,5 \%)$ y fumar $(4,7 \%)$. En porcentajes, la «secularización» (entendida en este sentido restringido) de determinadas prácticas y prescripciones sociales y religiosas era más importante también entre los residentes en localidades de menor número de habitantes (esto, como veremos, se corresponde con la mayor dificultad de asistencia a celebraciones conjuntas y al menor control ejercido por la comunidad) y los que tienen pareja española. Por otro lado, los que menos habían modificado estas prácticas eran los que tenían pareja de su mismo país de origen.

La religión, a pesar de que también puede ser uno de los aspectos donde se dé aculturación, se puede convertir en catalizador de la cultura propia como reacción a una sociedad que los quiere aculturar o que perciben que les quiere aculturar y que les ofrece pocas oportunidades. En este sentido, la flexibilización o abandono por algunos de la práctica en aspectos como la oración, el Ramadán o el consumo de determinados alimentos impuros justifica y anima la reacción de otros musulmanes que lo ven como una amenaza. Para evitar este proceso desarraigador entre «sus hermanos» crean una mezquita, o pretenden hacerlo, e intentan estructurar de nuevo là comunidad. Este retorno se hace a través del proselitismo del imán y de todos los musulmanes, que deben ayudar y corregir los errores de otros musulmanes. De esta forma, en el momento en que se asienta un colectivo lo suficientemente importante en una población o zona, surge la necesidad de crear un espacio donde practicar juntos (cuando viven en tierra no

\footnotetext{
${ }^{4}$ En este trabajo, además de analizar la implantación de los centros de oración se profundizó en el comportamiento religioso de los musulmanes (Garreta, 1998).
} 
musulmana el Islam se pronuncia en esta línea). A menudo, la llegada al nuevo contexto (no musulmán laico, pero impregnado de religiosidad) modifica la práctica, pero el contacto con estos núcleos o con otros musulmanes que siguen el Islam favorece la recuperación. Pero no siempre es tan sencillo, porque las opciones personales y los conflictos entre los diferentes grados de seguimiento del Islam pueden aglutinar, pero también desencadenar el distanciamiento.

Para complementar lo anterior, también se analizó la intención de hacer perdurar la religión en las posteriores generaciones. Más de la mitad de los entrevistados (58\%), especialmente los que tienen pareja de su mismo país de origen y que comparten religión $(64,5 \%)$, preferían continuar la tradición. Pero este interés también se relacionaba con la práctica de los padres: los practicantes eran los más interesados en que sus hijos siguieran la tradición (71\%), mientras que los no practicantes eran los más flexibles en lo referente a la adaptación de la práctica religiosa musulmana al nuevo contexto social y cultural (15\%). Siguiendo esta tendencia, los que consideraban que era necesario adaptar la religión al nuevo contexto de residencia (condiciones laborales, sociales, etc.) $(9,4 \%)$ eran principalmente residentes en las poblaciones con menor número de habitantes - recordemos que se trataba de los que más habían modificado sus prácticas. Por último, otra opción tomada es dar libertad a los hijos $(25,2 \%)$; aquí los residentes en poblaciones de mayor tamaño (el $41,5 \%$ de las de más de cincuenta mil habitantes), los que tienen pareja española (35,5\%) y los de África Negra $(32,6 \%)$ eran los que más a favor se mostraban.

La transmisión del Islam a las nuevas generaciones se realiza principalmente en casa, a pesar de que la asociación islámica juega un papel destacado. Pero la actitud de todos los padres no es idéntica. Hay varias posiciones: desde los que prefieren llevar a sus hijos a su lugar de origen y que sigan el Islam allí para no tener que escolarizarlos aquí y de paso esquivar la posibilidad de perder o sacrificar su creencia y su cultura, a los que quieren transmitir la religión como lo hacían en su país, poco a poco desde la infancia y según los pasos que ellos mismos siguieron. La renuncia a transmitir el Islam a los hijos no apareció en ninguna de nuestras entrevistas, aunque sí es cierto que algunos flexibilizan el seguimiento y dan una teórica libertad de elección a lo hijos. Pero la intención de transmitir los propios valores religiosos a los descendientes y el mantenimiento de las prácticas puede chocar con el comportamiento y la opción que tomen esas nuevas generaciones. El requerimiento paterno y comunitario de continuar con el cumplimiento de determinadas prescripciones, especialmente entre las mujeres, puede conducir a conflictos generacionales. Los jóvenes que han vivido entre dos culturas pueden no estar dispuestos a seguir algunas de las prescripciones religiosas y sociales que evidenciarían su diferencia (por ejemplo, el uso del chador) o rechazar determinadas prácticas culturales, como que los padres acuerden el matrimonio de la hija - de hecho ya se ha detectado la presencia de estas adolescentes o mujeres en los centros de acogida catalanes (Garreta, 1999a). 


\section{LAS COMUNIDADES ISLÁMICAS EN CATALUÑA}

Fruto del interés que nos despertó el anterior estudio, iniciamos un análisis de lo que algunos han llamado el «trasplantamiento», concepto criticado en la actualidad, o implantación del Islam, en nuestro caso en Cataluña. El estudio, hasta ahora inédito, se llevó a cabo durante los años 1998 y 1999 con el fin de conocer la dimensión de la presencia islámica en Cataluña y la dinámica de su desarrollo hasta la actualidad. Se realizaron cuarenta y una entrevistas en profundidad a imanes o representantes de las mezquitas (cuando los primeros eran de imposible localización) repartidos por toda la geografía catalana en función de la densidad de centros existentes ${ }^{5}$ y nos acercamos a la realidad que viven estos colectivos respecto a cuestiones como el número de las mezquitas existentes, su proceso de creación, los objetivos y las actividades que llevan a cabo, sus usuarios y los grados de práctica, la figura y el papel del imán o la opinión que les merece la situación de su cultura, y más en concreto la escolarización de sus hijos, en Cataluña.

\section{Las mezquitas existentes en Cataluña}

Para detectar el número de mezquitas existentes en territorio catalán, partimos del Registre d'Associacions del Departament de Justícia de la Generalitat de Catalunya, que refleja en sus inscripciones el incremento del interés por convertir las mezquitas u oratorios ${ }^{6}$ en asociaciones culturales no religiosas. Así, si de 1993 a 1996, Moreras (1996) indicaba que había inscritas más de quince asociaciones, en la actualidad hemos contabilizado un total de treinta y seis, a lo que habría que añadir el interés en inscribirse expresado por muchos de nuestros entrevistados que aún no lo estaban. También nos permitió observar que la distribución no es uniforme en todo el territorio: las comarcas del Barcelonès y Baix Llobregat son las que concentran, con diferencia, el mayor número de asociaciones registradas, que, como veremos más adelante, se corresponde también con el

\footnotetext{
${ }^{5}$ El trabajo de campo finalizó con cuatro entrevistas en las comarcas de Lleida, ocho en las de Tarragona, nueve en las de Girona y veinte en las de Barcelona.

${ }^{6}$ Una de las primeras cuestiones que debemos definir es lo que se entiende por mezquita y centro de oración. A pesar de que no es lo mismo, en la práctica los entrevistados lo utilizan en la mayoría de casos indistintamente para referirse a sus centros, aunque es cierto que referirse a éstos como mezquitas es lo más frecuente. Algunos entrevistados, cuando les preguntamos, consideran que sólo se debe hablar de mezquitas, aunque otros dicen que los espacios que tienen no acaban de serlo, ya que no cuentan con la infraestructura arquitectónica y se debería hablar de oratorios o centros de oración. Nosotros, a partir de este momento, los llamaremos exclusivamente mezquitas siendo conscientes de esta discrepancia de opiniones.
} 
mayor número de mezquitas disponibles, estén o no registradas. Como es lógico, esta presencia se relaciona con la mayor concentración de inmigrantes musulmanes y con su asentamiento en esos territorios.

Otro registro indispensable para complementar la información anterior es el Registro Nacional de Asociaciones del Ministerio del Interior. Comparando el listado facilitado por este ministerio (fecha 21 de abril de 1999) con el anterior no aparece ninguna asociación diferente de las que ya habíamos detectado, y prácticamente todas se repiten, a pesar de que alguna sólo consta en el registro catalán. Por último, tampoco podemos olvidar las inscritas como entidades religiosas en la Dirección General de Asuntos Religiosos del Ministerio de Justicia. En este registro (a fecha 18 de mayo de 1999) constan ciento veintisiete entidades repartidas por toda la geografía española, evidentemente no distribuidas uniformemente, ya que unas Comunidades Autónomas cuentan con mayor número que otras - donde hay mayor número es en Andalucía (treinta y ocho) y en Madrid (veintinueve). En Cataluña hay veintiuna, repartidas también irregularmente por toda la geografía. Tenemos que precisar que la mayoría no se encontraba en ninguno de los dos anteriores registros.

En general, si no se registran en los listados oficiales puede atribuirse al desconocimiento de los procedimientos que deben seguirse. En cuanto a la tendencia a inscribirse como asociación cultural más que religiosa se explica, en parte, por la información que reciben de las personas a las que se dirigen cuando pretenden regularizar su situación. Parece que les aconsejan que se registren como asociación cultural porque se supone que les reportará mayores ventajas. Es lo que ha sucedido con frecuencia entre nuestros interlocutores. Del trabajo de campo de Moreras (1999) se desprendía al respecto que, a veces, el registro como asociación cultural se convierte en un paso provisional para registrarse posteriormente como entidad religiosa. En unas ocasiones se debe a que la misma administración local las deriva hacia la Generalitat de Cataluña - parece que la administración central se ve lejana-; en otras a que esta tramitación resulta más sencilla como una forma de evitar la dependencia de otras asociaciones musulmanas de ámbito local o nacional; y, en último lugar, también se puede ver una cierta estrategia de invisibilidad: la no utilización de palabras como islámico o musulmán es un indicador del deseo de pasar desapercibido.

Pero no estar registrado no quiere decir no existir. Hay mezquitas que no se han registrado porque aún se están gestando o tienen un funcionamiento inestable y prefieren esperar y, sin embargo, se comportan de forma similar a las que lo están. Los entrevistados, en su mayoría, creen necesario registrarse como asociación o entidad religiosa, pero, sobre todo los que no lo están, consideran que antes deben estar consolidados y además recibir ayuda de mezquitas o personas que conozcan los trámites.

Dado que los registros oficiales no reflejaban el número real de centros islámicos en Cataluña, se nos planteó la siguiente pregunta: ¿cómo detectar los 
que no constaban en ningún listado?. La solución fue aprovechar las entrevistas para averiguar los que se conocían, que junto con las más de cien llamadas a ayuntamientos (que en muchos casos nos derivaron a otros servicios especializados), nos permitió obtener un censo muy realista de la cantidad de centros abiertos. Llegamos a contar hasta 97 en Cataluña, que, como en el caso de los registros mencionados, no se distribuyen de forma homogénea por la geografía. El siguiente mapa que visualiza el número de mezquitas que hay en cada comarca, con gradación de tramas, permite constatar que algunas comarcas, sobre todo las de la costa y de las provincias de Barcelona y Girona, concentran el mayor número. Las diferentes coronas de densidad también indican que, en las provincias citadas, su presencia va menguando de la costa hacia el interior. Así, por ejemplo, el Barcelonès, el Maresme y el Baix Llobregat se caracterizan por una mayor concentración; las siguen el Baix Empordà, l'Alt Empordà, el Gironès, la Selva, el Vallès Oriental, el Vallès Occidental y el Baix Penedès. Los lugares con pocas mezquitas, son comarcas como el Urgell, el Solsonès, el Pla d'Urgell, el Montsià, el Baix Ebre, el Ripollès, etc. Por otro lado, hay comarcas donde aún no existen: la Terra Alta, la Ribera d'Ebre, el Priorat, les Garrigues, l'Alt Camp, la Conca de Barberà, la Segarra, la Noguera, el Pallars Jussà, el Pallars Sobirà, el Alt Urgell, la Cerdanya, la Alta Ribagorça y el Vall d'Aran, pero eso no significa que no haya población musulmana, sólo que no se han asociado, quizás por ser insuficientes sus miembros, pero ciertamente, en algunas de las localidades de estas comarcas, nos consta que ya se empiezan a movilizar a pesar de que aún no se hayan iniciado gestiones o las mismas estén en trámites.

Una de las primeras conclusiones que podemos extraer de los datos obtenidos y del siguiente mapa es la importante presencia del Islam en Cataluña y el alto crecimiento de las mezquitas en todas las comarcas catalanas donde hay musulmanes, especialmente en aquéllas donde existe un número suficiente y están motivados por la continuidad de su religión y de su cultura. Si comparamos el anterior mapa con uno de la distribución de los inmigrantes musulmanes en Cataluña observaríamos, como es lógico, la correspondencia y proporcionalidad con su número.

\section{El proceso de creación de mezquitas}

El proceso de creación de la mayoría de las mezquitas visitadas es semejante, aunque hay que tener muy presente en qué época se crearon. Las hay que aparecieron durante los años setenta e inicios de los ochenta, que es cuando se crearon los primeros centros. De esta etapa es uno de los centros que han tenido un papel más relevante en Cataluña, el Centro Islámico Internacional de Control, que surge, como en todos los casos analizados, de la comunidad formada no por inmigrantes económicos, que suele ser lo habitual, sino auspiciado en su origen por estudiantes extranjeros de creencia musulmana, que en 1971 consideraron 


\section{Mapa 1.}

Existencia de mezquitas por comarcas

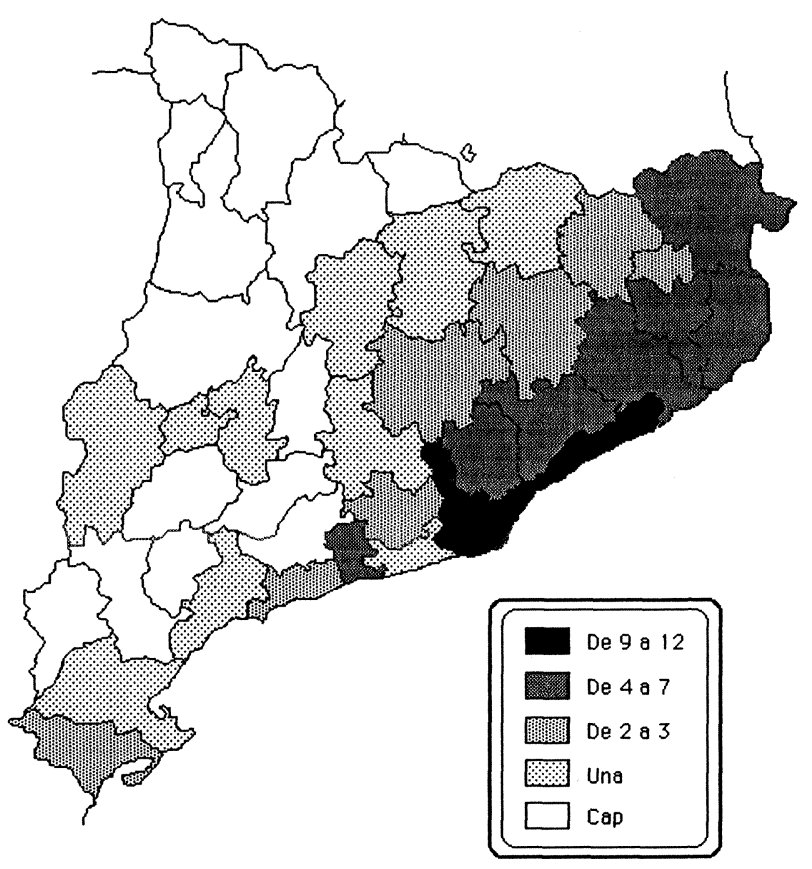

necesario crear un centro donde practicar su religión, reunirse y relacionarse. Otra de las primeras mezquitas que se crearon en Cataluña fue la de Táriq Ibn Zyad (también en Barcelona ciudad), que, como la anterior, ha acabado siendo un polo de atracción de otras mezquitas e imanes catalanes.

De mediados de los ochenta, entre 1984 y 1987, periodo que Moreras denomina primera fase de dispersión, son tres de los centros con que hemos contactado e indican un incremento y asentamiento de musulmanes más allá de la ciudad de Barcelona ${ }^{7}$, y que también se fundaron con el objetivo de encontrar un espacio para la práctica religiosa y la convivencia - principalmente de los hombres.

Los años siguientes hasta 1992, etapa de dispersión, visibilización y estabilización comunitaria que diría Moreras, estarían representados por la creación de seis de las cuarenta y una mezquitas en que nos hemos centrado. Se distinguen de las anteriores en no ubicarse exclusivamente en las poblaciones de las comar-

\footnotetext{
${ }^{7}$ Viladecans, Sant Vicenç dels Horts y Castelldefels.
} 
cas de Barcelona (Girona, Roses y Lleida). En cuanto a los argumentos utilizados para justificar la necesidad de crear una mezquita, además de los mencionados, aparece el miedo al rechazo al que se enfrentan, buscando un espacio propio donde sentirse más cómodos o que les permita seguir con sus hábitos y donde los lazos y apoyos son solidarios. También se asocian los inmigrantes cuando se busca una identificación entre lo que se dice en la mezquita y lo que se defiende a título personal. Cuando aparecen divergencias y conflictos entre los miembros de una asociación, sobre el grado de seguimiento del Islam se tiende a la división. Y a la inversa, si sus miembros se identifican y económicamente es posible, se unen. Así que no es difícil encontrarse con fusiones y fisiones. Por último hay otro motivo que anteriormente no habíamos detectado: el miedo a la pérdida de la religión y la cultura de las nuevas generaciones.

La última etapa, llamada de progresiva regularización, que se iniciaría hacia 1992, se caracteriza por el importante incremento de centros ${ }^{8}$, aunque no todos se registren. Éstos, además de repetir las motivaciones de los anteriores para abrir un centro, destacan la vertiente educativa, sobre todo para los más jóvenes. La creciente presencia de niños y adolescentes motiva que muchos padres, que en algún caso dicen no haberlo pensado antes de adoptar este rol, consideren una prioridad la transmisión de su religión y cultura y se movilicen para evitar la pérdida de sus propias raíces. Pero la creación de la mezquita, no sólo depende del ánimo de unos cuantos. Es necesario, además, que el número de musulmanes residentes en una localidad o zona de atracción, más el de transeúntes, sea suficiente para mantener económicamente la sede religiosa-cultural. Intervienen, como factores catalizadores o disuasivos, la administración pública y los vecinos, sin duda determinantes a la hora de facilitar o dificultar su instalación. Normalmente los ayuntamientos y los vecinos no lo viven como un problema: unos porque se limitan a la tramitación de documentos, y los otros a «tolerar» su presencia, ahora bien, con un amplio abanico de situaciones y actitudes. Sólo como ejemplo de situaciones de conflicto vividas, recordemos lo sucedido en el mes de julio del presente año en la población gerundense de Banyoles.

Como síntesis de nuestros resultados podríamos decir que las motivaciones que llevan a la creación de una mezquita, y que se relacionan con los objetivos y actividades que tienen, son: seguir las prácticas religiosas, especialmente las colectivas; organizar, conforme a las pautas de su religión, la vida social entre ellos y con los «demás», tanto espiritual, como económica... que algunos más que otros consideran que se debe preservar para evitar el abandono de la moral,

\footnotetext{
${ }^{8}$ Así en el año 1992 se crean tres centros de los cuarenta y uno, en 1993 cuatro, en 1994 cinco, en 1995 tres, en 1996 tres, en 1997 cinco y en 1998 siete.
} 
de la vestimenta, del rol tradicional de la mujer, etc.; evitar la pérdida de la cultura y de la religión; transmitir a las siguientes generaciones la religión, además de la tradición cultural y la lengua; reconstruir la identidad perdida; y ayudarse o ayudar a los transeúntes que lo demandan. Es evidente que según el interlocutor, o la fase de desarrollo de la mezquita, se insiste en uno u otro de los objetivos y motivaciones; pero un punto convergente es la defensa de su cultura y, ante todo, de su religión.

\section{Los objetivos y las actividades de las mezquitas}

Los objetivos y las actividades que se suelen realizar se pueden agrupar en dos grandes categorías: religiosas y educativas. El hecho de que las mezquitas a menudo sean asociaciones, o tengan la intención de serlo, da lugar a que añadan otros objetivos a los meramente religiosos. En el aspecto religioso, rezar cinco veces diarias y en especial la oración del viernes, la celebración del Ramadán y la fiesta del cordero, entre otras, son las actividades más habituales, aunque a veces dependa del horario de las mezquitas. No todos los centros se pueden permitir abrir todo el día; sólo los que pueden afrontar el gasto de un imán a tiempo completo, o los que tienen uno, frecuéntemente en régimen temporal, que al estar en el paro, de baja o jubilado, puede dedicar todo el día a desempeñar esta función. El resto, ya sea porque les es costoso un imán o porque durante la jornada laboral acuden pocos asistentes, sólo abren fuera del horario laboral, y los viernes, de obligada asistencia, se hace un esfuerzo para mantenerlos abiertos, pero no siempre es posible. Lo más habitual es que abran cuando es festivo para todos, los sábados y los domingos. El horario de clases, en consecuencia, se encuentra también supeditado a estas condiciones.

El objetivo educativo resulta más interesante para aquellas mezquitas que tienen una importante presencia de familias con hijos y en las que llevan más años funcionando. Lo más frecuente es querer transmitir la religión a los niños y adolescentes'. Respecto los adultos se considera que con la práctica cotidiana ya tienen suficiente y no es necesario ningún refuerzo al margen de las oraciones, la conferencia del viernes o las reuniones en que hablan de religión y enseñarles el idioma (principalmente el árabe, salvo cuando hay otra lengua mayoritaria), aun-

\footnotetext{
9 Veamos cómo lo expresa el entrevistado de una mezquita de Lleida creada en 1998, que aunque de joven creación dice: «¿Actividades? Por ejemplo enseñar a los niños el idioma árabe, eso también dentro de las actividades y objetivos de la asociación, dentro de la mezquita, porque es una cosa que veo que estamos perdiendo. Los niños están perdiendo el idioma madre... entonces es que hay una actividad de esto. La mezquita, como es un centro, asociación, es lo mismo, pues entonces pretendemos que los niños aprendan. Lo hacemos tres horas los domingos».
} 
que también es cierto que a medio y largo plazo se preocupan por organizar clases específicas para adultos. Esporádicamente se celebran conferencias de otros imanes o sabios (personas muy conocedoras de la religión) para profundizar en cuestiones de interés común. Estos conferenciantes pueden formar parte de la misma comunidad musulmana catalana o venir del extranjero, por ejemplo de Marruecos, patrocinados por este gobierno ${ }^{10}$. Aparte de la religión se tratan temas relacionados con la cultura, ya sea de Marruecos o de otro país (según la procedencia del imán y los fieles) o de alguna de las minorías étnicas".

Finalmente no debemos olvidar otro objetivo menos mencionado, pero que existe y se traduce en actuaciones puntuales. Nos referimos a la ayuda que se prestan entre ellos, y que puede ser económica (a transeúntes o a otras mezquitas para su inicio o consolidación), jurídica (tramitación de documentación individual o para registrar la mezquita) o, evidentemente, moral y espiritual.

\section{¿Quiénes son los que frecuentan las mezquitas catalanas?}

A las mezquitas acuden musulmanes de orígenes muy diversos, pero si nos ceñimos a cada centro como ente particular observamos que hay una estrecha relación en el perfil de los musulmanes que residen en la zona e incluso lugar donde se halla el centro. En primer lugar, hemos notado que la tónica general es que la procedencia del imán está determinada por la mayoritaria de los fieles. Si son marroquíes, el imán también lo será, o pakistaníes, como en una de Barcelona, o bien originales de África Negra (una en Lleida), ya sean de Gambia, Senegal o Malí. Hay excepciones, casi anecdóticas, como la de dos imanes, los de las mezquitas más veteranas de Barcelona, que han conseguido la nacionalidad española.

En cuanto a la nacionalidad de origen de los usuarios, muchos de los centros tienen una clara mayoría de marroquíes (por ejemplo, las mezquitas de Martorell, Vic, Sant Vicenç dels Horts, Sant Boi del Llobregat, etc.), aunque algunas agrupan además musulmanes procedentes de otros países (por ejemplo Táriq Ibn Zyad de Barcelona ciudad, Ennort de Viladecans, la Asociación Cultural Islámica Tajdid de Catalunya de Santa Coloma de Gramenet, etc.). Esta convivencia de

\footnotetext{
${ }^{10}$ Como ejemplo la entrevista realizada en Barcelona a una mezquita creada en 1986: «Viene un sabio. Hablamos. Le pagamos la ida y la vuelta. Y también hay que vienen del gobierno de Marruecos. El gobierno marroquí manda sabios para dar orientaciones y explicaciones del Islam durante el Ramadán. El gobierno paga. El año pasado vino. Este año, como tenemos mezquita nueva, no va a venir».

"El entrevistado de una mezquita de Tarragona creada en 1994 nos lo confirma al decir: «Alguna vez se organizan charlas sobre la cultura. De Marruecos. Los beréberes como tienen lengua diferente y vienen, se intenta que hagan alguna cosa, pero el árabe por el Corán».
} 
diferentes países de origen, pero sobre todo de diferentes zonas de origen de los africanos (Magreb y África negra), y etnias, niveles de riqueza... se explica porque el Islam no marca diferencias en este sentido. Es decir, las relaciones entre los que siguen la fe islámica no pueden estar condicionadas por estos factores ${ }^{12}$. Ahora bien, la creencia y la práctica, y la consiguiente identificación como musulmán, pueden condicionar, y de hecho lo hacen, las relaciones interpersonales distinguiendo entre los que practican y son «buenos musulmanes», los que la han abandonado aunque sea temporalmente, y los no musulmanes. En estas condiciones el trato con un no musulmán, y especialmente ante el que ha abandonado u olvidado ciertos aspectos del Islam, es un factor que puede adquirir protagonismo y provocar una identidad exteriorizada.

Respecto al número de asistentes habituales a las mezquitas, lo primero que hemos podido constatar es que varía según sean días laborales o festivos, o si las oraciones deben realizarse durante la jornada laboral o fuera de ella. Esto responde a que su práctica está sujeta al contexto no musulmán (aunque no siempre tengan que ir a la mezquita, el viernes es insoslayable orar en grupo). Por tanto, ante la dinámica laboral y los horarios de la sociedad de acogida (donde el día festivo no es el viernes sino el domingo) y hacer compatible la práctica religiosa con el trabajo y la vida en Cataluña, han tenido que adaptarse y flexibilizar sus ritos, en la medida de lo posible, a las costumbres autóctonas. En este sentido, el Corán da cierto margen. Por eso, pocas personas asisten a las oraciones que coinciden con el horario laboral y, en cambio, se incrementan las que se realizan antes y después del trabajo, aún más el fin de semana. Esta asistencia tan irregular imposibilita que alguien haga de imán a tiempo completo o que se tenga abierto el centro todo el día. De ahí que la afluencia según mezquitas sea también más variable. Algunas las visitan regularmente de veinte a cincuenta personas, otras tienen un número mayor de seguidores, en relación directa con la presencia de un mayor número de musulmanes en la población en que se ubica.

Una característica común es que los usuarios son principalmente hombres. En las mezquitas catalanas, las mujeres en contadas ocasiones tienen el espacio adecuado para su participación (y en ese caso las ubican en una zona separada, generalmente detrás de los hombres). Ante esta limitación, realizan sus oraciones en la intimidad de sus hogares o, en el mejor de los casos, en reuniones femeninas o fiestas caseras, siempre en una vivienda que tenga espacio para albergar el grupo. Como muchas de las mezquitas estudiadas carecen de superfi-

\footnotetext{
${ }^{12}$ Otra cuestión es que las relaciones entre inmigrantes de diferentes países, y especialmente de estas dos zonas de África, sea fluida. La existencia de imágenes mutuas, estereotipos... condiciona las relaciones que se establecen (Garreta, 1999) e incluso, cuando es posible, la creación de mezquitas diferenciadas por este criterio.
} 
cie suficientes, no es de extrañar que esta falta sea uno de los principales argumentos esgrimidos cuando se les pregunta por qué no disponen de un área propia para sus rezos las mujeres. Los pocos centros que cuentan con el espacio adecuado acostumbran a ser las mezquitas que llevan más tiempo funcionando y que están instaladas en ciudades con un número importante de musulmanes. Las que no ofrecen esta sección, con una más o menos clara intención de que a medio o largo plazo exista, señalan la necesidad de rezar separados hombres y mujeres. Parece pues que la reflexión de Dassetto en el sentido de que la mezquita se puede ver como una forma de relegitimación masculina (paterna y marital) que se estaba perdiendo en el proceso de secularización/occidentalización, adquiere plena significación.

\section{Musulmanes practicantes y musulmanes no practicantes}

Como queda dicho, las circunstancias laborales y las costumbres de la sociedad de acogida, son factores que influyen en la práctica religiosa de los musulmanes y que pueden cambiar sus propios hábitos. Aun así muchos continúan practicando su religión, algunos la abandonan total o temporalmente, y otros que en su país no la practicaban nada o poco, de nuevo la abrazan aquí ${ }^{13}$. Del estudio de Lleida y Huesca hemos extraído que son varios los elementos que determinan esas tendencias: la elección personal, los contactos con otros musulmanes, las circunstancias vividas y las dificultades que la sociedad de acogida pone al seguimiento de los preceptos, la distancia física con la mezquita (factor cada vez menos importante dada su progresiva proliferación), etc. Entre los entrevistados del estudio de toda Cataluña, existen diferentes opiniones sobre el número de musulmanes que abandonan la práctica. Algunos interlocutores reconocen que puede darse un retroceso, temporal en cualquier caso, con respecto a las prácticas de origen, porque lo más frecuente es el retorno a la práctica de aquellos que eran practicantes en origen ${ }^{14}$.

\footnotetext{
${ }^{13}$ En una entrevista en una mezquita de la provincia de Barcelona (a partir de este momento al transcribir estos fragmentos los situaremos por provincias) creada en 1993 nos decían: «Aquí hay más libertad. Si no me ven, puedo hacer una tontería y la hago. La mayoría que en su país no rezaban, no rezan. Hay excepciones que no rezaban y aquí sí. $Y$ al revés. Son excepciones, pero existen».

${ }^{14}$ Un entrevistado de una mezquita de Girona instalada en 1992 nos decía: «Tenga en cuenta que aunque estuviera en su país, un practicante, uno que es creyente, esta persona en la vida dejará de hacer lo que está obligado a hacer. Creo que la persona que sale, pasa todos los riesgos, vende todo lo que tiene en Marruecos, no consigue un visado, pasa al país vecino y sufre calamidades, esta persona el día que tenga todo legalizado, si es musulmán, no dejará de hacer lo que hacía en su tierra. El que no practica es el musulmán de boca, el que no practica y dice que es musulmán. Pero es verdad que puede haber alguno que igual allí estaban practicando y no lo harán igual aquí».
} 
Las cuestiones espirituales, sin duda, son individuales e intransferibles porque dependen en gran medida de la fe de cada persona, pero estas circunstancias en el caso de los creyentes musulmanes nos han permitido observar que hay una serie de factores que condicionan la continuidad en las creencias: la edad (los más jóvenes son los que pueden ser «tentados» por el modelo de la sociedad de acogida ${ }^{15}$ ), el contexto en que se vive, que condiciona o limita la posibilidad de practicar $^{16}$, la existencia o no de mezquita, las amistades, el tener o no familia y especialmente hijos, etc. En conjunto o por separado estos elementos pueden contribuir a que se pierda algo de fe, y en estos casos la lucha que deben mantener es constante como expresa un imán de Barcelona: «Hay algunos, poquillos, que están débiles de fe (...) tenemos nuestra propia enseñanza, nuestra propia cultura, desde el nacimiento hemos crecido como musulmanes. Lo que entendemos es el Corán y nuestro idioma es el árabe. Nuestra creencia, nuestra civilización, nuestra cultura es todo entre las leyes del Islam. Es como si cogieras varias cosas y las metes en alquitrán, se tienen que volver negras. Esto, la crianza, el despertar, el andar, está dentro del Islam. Yo cuando voy a comer soy practicante, debo decir el nombre de Dios. Todo está impregnado».

Las dificultades descritas y otras en las que no nos hemos detenido condicionan absolutamente el seguimiento de la práctica. Es evidente que para ellos representa una prueba de fuego salir de sus países y encontrarse con una nueva realidad que se desarrolla con unos parámetros de vida cotidiana diferentes. Los años noventa y seguramente los primeros del nuevo milenio serán un periodo de ajuste y articulación de las diferentes posiciones, con respecto a las relaciones y

\footnotetext{
${ }^{15}$ En Girona, en otra entrevista, en este caso de una mezquita abierta en 1994, nos decían que: «Muchos vienen aquí y se olvidan de todo, no rezan ni nada. En su país su padre musulmán, su abuelo musulmán, él también, pero aquí cambia. Vienen con dieciocho o diecinueve años y lo encuentran todo más fácil y se olvidan de todo. No son todos, bueno. Yo te hablo ya que llevo mucho tiempo y al no haber mezquita... pero gracias a Dios ahora hay meżquita, sabes. Antes no estaba tan bien, ahora mejor».

${ }^{16}$ Así un entrevistado de una mezquita de Tarragona fundada en 1995 dice: «Cuando llegan a un país no musulmán algunos van a la manera del país en que se entra. Van a beber, bailar, las mujeres están en la calle. Si ven esas cosas, muy fácil, y esa libertad, se meten y pierden la práctica. (...) Vuelven algunos, pero pocos. Los que van mal. La mujer peor todavía. Si sale y ve lo que hay en la calle se pierde, se va a la manera de lo que ve en la calle». Otro de Lleida tiene un discurso parecido: «Esto es cosa de la vida, hay gente que está más... gente que quiere vivir la vida, que piensa que son cuatro días y sólo quieren disfrutar. Otros son ignorantes, no tienen bastante conocimiento, cultura. Algunos vienen, hacen la oración y cuando salen lo dejan todo aquí dentro. Un musulmán no puede hacer esto. El comportamiento, la creencia... es dentro y fuera. Hay gente que quieren vivir la vida como la viven aquí. Y... es difícil. Al llegar aquí se encuentran otro mundo y cambian mucho».
} 
los intercambios que se establecen. El deseo de no perder las raíces, sin embargo, no es un obstáculo para que la situación del Islam en Europa, España y Cataluña esté en evolución. La dinámica de su instalación, la actitud de la sociedad y de la administración receptora, etc., son condicionantes con tantas caras, que cuando un musulmán entra en este nuevo contexto debe enfrentarse a más de un escollo.

Cuando alguien abandona parcial o totalmente las prácticas religiosas, la comunidad pone en marcha dos mecanismos: el control y el proselitismo. El control de la asistencia propiamente no existe, es decir, no se pasa lista para ver quién asiste y quién no. La única lista que utilizan, en algunos centros, es la de los contribuyentes. Otra cosa es que un compañero que asista con regularidad deje de hacerlo sin comunicar el porqué. Entonces la situación se suele resol$\operatorname{ver}^{17}$. En estos casos todo musulmán, sea o no el imán, tiene la obligación de hablar y convencer a un hermano que se encuentre perdido. El incumplimiento de este deber se convierte en una carga que deberá soportar en el futuro ${ }^{18}$. Animar, explicar, recomendar que es necesario visitar la mezquita, o al menos que la conozca, es una obligación de todos que muchos cumplen. El control de la comunidad para con los que se ausentan puede estar más o menos organizado: así encontramos desde los que lo hacen esporádicamente y sólo cuando encuentran la ocasión, a los que reconocen acometer esta tarea sistemáticamente. Por ejemplo, algunas tardes y los fines de semana dos o tres personas realizan estas visitas $\mathrm{y}$ van a ver a los enfermos ${ }^{19}$. En este punto también hemos detectado la dependencia de algunos centros respecto a los mayores de Barcelona, ya que estas visitas también se efectúan en algunas ocasiones acompañados por sus represen$\operatorname{tantes}^{20}$. La insistencia es más evidente y necesaria entre aquellos que necesitan

\footnotetext{
${ }^{17}$ Así nos lo explica un entrevistado de una mezquita de Barcelona creada el año 1985: «El día que no va, si vas siempre y no vas, preguntan, mandan a alguien a saber por qué no vas. Si uno está malo. Ver, si viene siempre, qué le pasa».

${ }^{18}$ Como ejemplo, un fragmento de un entrevistado de una mezquita de Lleida (1990): «Cuando ves a uno que está haciendo algo que no le favorece, que no está bien... que no tiene que hacer. $\mathrm{Si}$ tú eres musulmán, y él también, y lo dejas, tú no has cumplido. Debes aconsejar a tu hermano hasta que lo deje. Si tú puedes alejarlo, le aconsejas hasta que el hermano deja esta cosa... si él tiene pecado compartirá contigo este pecado ya que no has hecho nada para evitarlo».

${ }^{19} \mathrm{El}$ entrevistado de una de Barcelona (1993) nos sirve como ejemplo: «Todas las tardes hacemos una reunión. Todos somos mensajeros de Dios, tenemos nuestra responsabilidad. Por las tardes, como hoy, hacemos una pequeña reunión y vamos a visitar a los jóvenes que están en los bares, que el ambiente les ha podido. Todos tenemos nuestra parte de responsabilidad».

${ }^{20}$ En esta dirección va el discurso del entrevistado en la mezquita de Girona de 1995: «Vienen compañeros de Barcelona o de Gerona y preguntan cómo está el pueblo, y así... Y preguntan si hay alguno que no viene a la mezquita y vamos a visitarle. Alguien que no practique la religión, y vamos a su casa, y hola, qué tal va eso... Y los compañeros hablan con aquella persona y si Dios quiere viene y practica la religión».
} 
de más seguidores para mantener la mezquita, desde un punto de vista económico (pago del alquiler o hipoteca del local, luz, agua, etc.). Las aportaciones económicas, siempre voluntarias, en algunos casos, pocos, puede frenar la asistencia. El temor a que se les exija un dinero que no se puede o quiere pagar hace que algunos no aparezcan por los locales - este hecho es más mencionado en aquellas mezquitas que tienen gastos considerables, ya sea porque llevan a cabo muchas reformas y actividades o bien porque quieren comprar un local, que suele ser el gasto más elevado que deben afrontar ${ }^{21}$. Y también influye el ambiente (como ellos mismos dicen) que encuentran en la sede social, definido por lo que se predica, las personas que la frecuentan, sus países o zonas de procedencia, etc.

\section{La figura y el papel del imán}

El imán, persona que dirige la oración, organiza y orienta las prácticas, etc., es poco más, como entre todos los sunitas, que un simple gestor o vigilante de los principios fundamentales de la religión islámica, pero sin atribución sobrehumana. El imán es un hombre con reconocido prestigio en la comunidad, que conoce el Corán (generalmente de memoria), que lo puede interpretar y sabe explicarlo. En Cataluña, suele ser la persona con más estudios religiosos, y en general coincide con el nivel educativo más elevado, aunque la edad también puede ser un criterio $^{22}$. El imán es escogido para guiar, por lo cual siempre se busca al mejor posible, el más preparado, el que sepa explicarse mejor..., pero una vez más las circunstancias condicionan la elección. Mientras unos pueden permitirse traer a alguien muy preparado del país de origen, España o Cataluña ${ }^{2.3}$, otros deben confor-

\footnotetext{
${ }^{21}$ Sirva de ejemplo lo que dice el representante de una mezquita de Girona creada en 1991: «El motivo económico frena que vengan. Como quieren hacer muchas cosas y han comprado un terreno, se creen que les obligarán a pagar. Dicen que pagar es voluntario, pero, claro, no quieren venir si deberían pagar y no lo hacen».

${ }^{22}$ «Tenemos que estudiar el Corán. Estudiar el Corán y las leyes de Mahoma y entonces podrás ser el imán (...) Dentro de la mezquita, si conoces podrás ser el imán. Ellos van escuchando, escuchando, pero no puedes fallar pues no tienes los libros. Primero cogemos aquel señor que estudia mucho el Corán y las palabras, segundo aquel que estudia mucho lo mismo y es mayor de edad. Preferencia si ha estudiado y si es mayor de edad». (Entrevistado en una mezquita de Lleida abierta en 1998).

${ }^{23} \mathrm{El}$ imán de una de las mezquitas que lleva más años funcionando en Barcelona, desde 1971, nos describe cómo le nombraron: «Sé algo de la religión y así me nombraron. Es que el centro nuestro pertenece al Centro de Madrid, el Centro Islámico que está formado por cuatro delegaciones: Granada, Valencia, Barcelona y la sede central que está en Madrid. Entonces se me nombra como los otros, así viene el nombrar. Conocen uno y lo dicen ellos. (...) Los otros imanes son independientes, no dependen de Madrid. La mayoría de los centros religiosos son marroquíes y hay uno que sabe bien y lo nombran, o llamarán alguno de Marruecos».
} 
marse eligiendo entre los más próximos, entre los que asisten a la mezquita ${ }^{24}$.

Las relaciones que mantienen entre ellos, la coordinación, las visitas recíprocas, etc. son aspectos que generan más resistencias a la hora de hablar de ello. Aun así, hemos podido diferenciar hasta tres grupos: los imanes que apenas mantienen contacto con otros, los que realizan reuniones periódicas (acostumbran a ser mensuales) con imanes de mezquitas más o menos cercanas, y los que intentan ejercer, como ya apuntaba Moreras, influencia sobre otras mezquitas y de paso «adscribírselas». En este último grupo se encontrarían dos mezquitas de Barcelona ciudad. Por otro lado, los imanes que dicen no mantener ningún tipo de relación, a menudo se creen autosuficientes: consideran que sus conocimientos, más el recurso de los libros, les basta para guiar a su comunidad, y así evitan influencias externas que pueden ser, en su opinión, negativas. En cuanto a los que mantienen contactos con imanes próximos, la influencia que ejercen es más simétrica ${ }^{25}$. La proximidad entre mezquitas favorece una relación estrecha y un mayor contacto entre imanes, pero incluso así pueden surgir problemas y discrepancias. Es habitual, por otra parte, que las diferencias existentes en origen se trasplanten también a destino, así como los prejuicios, las construcciones de la diferencia, etc ${ }^{26}$.

\section{La cultura de origen y el Islam en Cataluña}

A pesar de que algunos entrevistados consideran que su cultura y religión no se ven afectadas por vivir en una sociedad marcadamente diferente, la mayoría refleja en sus palabras el miedo a la pérdida, especialmente, de la lengua y la religión. Les resulta difícil mantener la cultura de origen, y sobre todo destacan el peligro de la aculturación que sufren y que pueden sufrir mayormente sus

\footnotetext{
${ }^{24}$ En una mezquita creada el año noventa y dos en Girona así lo plantean: «Para mantener el imán hace falta dinero. Hay un marroquí aquí que ha estudiado un poco las ciencias islámicas y lo hace. Cuando puede viene y si no... si tiene tiempo viene, si no lo hace Dios, bien un voluntario. Imán somos todos, yo puedo fallar si tengo trabajo, entonces es él el encargado, siempre que sepa oración y dar un discurso en la oración del viernes».

${ }^{25}$ «Calafell, Roda de Berà, Tarragona, Valls... hay otras. Se reúnen a veces los responsables allí donde toca. El primer sábado de mes tienen una reunión en una población. Hablan, charlan... los responsables de cómo arreglar las cosas, cómo presentarse aquí» (Imán de la mezquita de Tarragona creada en 1994).

${ }^{26}$ «Con la otra mezquita de aquí somos hermanos, pero no! Son gente de África que aquí no. Son gambianos y nosotros en Marruecos. Ellos tienen un imán y nosotros otro. Nosotros hablamos árabe, el idioma de nuestro padre. Ellos tienen otro idioma, son país. No vamos bien. Además estamos nosotros bien». (Imán de Girona de una mezquita fundada en 1997)
} 
mujeres y sus hijos. Parece que la reproducción del rol femenino en destino se hace difícil, a pesar de los intentos masculinos de que no se pierda. Hay una serie de cambios que se resisten a aceptar y a veces la forma de evitar este peligro es el aislamiento de la mujer, el recogimiento en la casa limitando al máximo sus relaciones ${ }^{27}$.

El conflicto cultural se observa en diferentes situaciones de la vida cotidiana (la vestimenta, los trámites administrativos, el comportamiento «no adecuado» de los autóctonos, etc.) y algunos lo viven de una forma problemática, aunque no todos $^{28}$. El asociacionismo y la creación de mezquitas es su respuesta a la tensión que les produce la implantación en un contexto adverso, en cuanto que es diferente. Ejemplificándolo con lo sucedido en otros países europeos, donde dicen que los inmigrantes han perdido su cultura y se han disuelto en la sociedad de acogida olvidando demasiado de su identidad, se contempla la unión como una forma de continuar la prácticas y la tradición. Pero la realidad es tozuda, y el asociacionismo, a pesar de que algunos lo vean como la solución a parte de sus problemas, por la precariedad en que viven y la falta de tiempo y personas que quieran dedicarse a ello, no resulta nada fácil de mantener (para profundizar en la situación del asociacionismo puede consultarse Garreta, 1998a).

Una de las peticiones más presentes es la necesidad de eliminar ciertos obstáculos que impiden actualmente ser musulmán en una sociedad laica, pero marcadamente impregnada de la religión católica ${ }^{29}$. En la dirección encarnizada

\footnotetext{
${ }^{27}$ De esta forma expresa esta vivencia el entrevistado de la mezquita de Tarragona de 1995: «Hay personas que entran en el bar, allí se fuma, hay mujeres... no se debe entrar en el bar. Hay que vestir también a nuestra manera, las mujeres deben ir que no se ve nada. Esto es lo que no entendemos, este cambio en las mujeres. (...) La mujer puede trabajar fuera... se puede trabajar fuera de casa pero siempre entre mujeres. Pero mejor no trabaja. Mejor en casa, se preocupa de dentro de casa (...) Difícil ver cómo está como aquí. Pero hay musulmán y musulmán. Hay que van a su manera musulmán. El musulmán-musulmán tiene una vida difícil aquí, pues como visten las mujeres, no puede ver esas cosas, no puede mirar. Tiene un sentimiento como los demás. Como visten las mujeres de España y otros países, le da... no sé, no puede mirar. Tiene una vida difícil. Aquí, que hay más, más, van más destapadas. El problema grande es las mujeres, lo demás menos, porque le hace mal al hombre».

${ }^{28}$ Como ejemplo nos sirven las palabras del imán de la mezquita de Barcelona abierta en 1971: «Es triste lo que pasa con estos temas. Uno se pone lo que le da la gana, como una monja. Deben dejar elegir. Nosotros aceptamos el nudismo, no decimos nada, no ponemos ningún problema y la sociedad no dice nada. Pero uno se cubre la cabeza... Tuvimos problemas con el gobierno de Barcelona, catalán. No aceptaban la foto en el permiso de residencia de las mujeres musulmanas y es toda la foto en la residencia de la mujer musulmana. Y en toda España aceptan. Fuimos a Madrid y al final la aceptaron. Llevan el pañuelo, pocas se tapan todo, aquí nadie casi se tapa el pelo».

${ }^{29}$ Esto se refleja en el discurso del imán de una mezquita de Barcelona creada en 1996: «Somos musulmanes de Cataluña, ya no somos inmigrantes. Tenemos que vivir con la leyes de Cataluña.
} 
a aproximar las diferencias culturales y religiosas se considera importante el conocimiento mutuo a través del diálogo y la comunicación, ambos bidireccionales. La eliminación de las imágenes arquetípicas y despectivas y su sustitución por una visión más objetiva de cómo es un musulmán, sería uno de los pasos más importantes para que este entendimiento fuera respetuoso por ambas partes. Aquí los medios de comunicación intervienen de un modo bastante simplista y parcial al presentar, con frecuencia, lo musulmán como fundamentalista, peligroso, etc. y sobredimensionando el fenómeno de la inmigración. Muchos consideran que el Islam, bien entendido, puede ser un factor de integración, ya que llenaría de contenido positivo y no vergonzante una frase que los autóctonos no siempre comprenden: «Soy un buen musulmán».

\section{La escolarización en Cataluña: valoración y actitudes ${ }^{30}$}

Nuestros entrevistados reconocen que la educación es necesaria y que la escuela tienen un importante papel en la formación de sus hijos, pero pasan rápidamente a manifestar, como cuando nos referíamos a la dimensión cultural, una serie de insatisfacciones y situaciones no deseadas con las que se ven obligados a convivir y contra las que intentan luchar, sin embargo, por regla general, con poco éxito.

En primer lugar, les preocupa que el comportamiento, las actitudes, la vestimenta... de la mujer occidental se interpongan en su propio código, especialmente en la escuela, y eso perjudique el mantenimiento y la transmisión de sus valo-

Con el tiempo (organización del tiempo) de Cataluña, obligaciones con Cataluña, somos ciudadanos de Cataluña (...) Formas a la gente como un ciudadano de Cataluña, no como musulmán o catalán. Que la gente sepa sus derechos y sus deberes».

${ }^{30}$ «A partir de una decisión del Consejo de Ministros de marzo de 1996, fruto del acuerdo entre el Gobierno español y las Comunidades Islámicas de España de 1992 (Ley 26/1992 de 10 de noviembre de 1992), los alumnos de primaria y secundaria podrán recibir enseñanza de religión musulmana en las mismas condiciones que los alumnos de confesión católica. Hasta ahora, durante la clase de religión católica, los alumnos de origen musulmán o bien seguían otras asignaturas (ética, conocimiento del entorno, etc.), o bien en otro espacio recibían refuerzo del catalán o de otras materias. Por su parte, los centros docentes deberán facilitar los locales adecuados para impartir estas clases. También se reconoce el derecho de la comunidad musulmana a establecer sus propios centros de enseñanza infantil, primaria y secundaria, y se les autoriza a organizar cursos de enseñanza religiosa en centros universitarios públicos, pudiendo utilizar los locales y medios de los mismos. En el momento de desarrollar el presente estudio, el desarrollo práctico del acuerdo se encontraba en fase de diseño y organización, ya que existían algunos aspectos que todavía no estaban resueltos: formación del profesorado o decidir a quién correspondía la financiación de estas actividades» (Crespo, 1997: 659). 
res a esposas, hijas, hermanas... ${ }^{31}$. Hay elementos de la dinámica escolar que no creen adecuados, como la alimentación, la vestimenta, etc., y eso crea tensiones entre dirección, profesorado, padres y comunidad musulmana que es necesario ir resolviendo ${ }^{32}$. El comportamiento de los otros niños, lo que aprenden en la escuela, en la calle y en la televisión, no parece responder a las expectativas de padres e imanes. Estos querrían ver reflejada su cultura en el currículum escolar, y que, hábitos que creen que también se aprenden en la escuela, como fumar, drogarse, utilizar un vocabulario soez..., desaparecieran.

Domina el miedo a la aculturación de las nuevas generaciones, y concretamente el temor a que pierdan su religión, o que la alteren excesivamente, y su lengua de origen. Algunos ya han tirado la toalla: «No tenemos miedo, más que miedo. La pérdida de la cultura es seguro». Ver cómo un hijo o una hija va dejando su cultura de lado y desconoce la lengua de los ancestros, es una experiencia amarga de desarraigo que viven como un conflicto de muy difícil solución ${ }^{33}$. Para prevenirlo piden que la escuela haga lo posible por mantener su

\footnotetext{
${ }^{31}$ En la mezquita, creada en 1998, de Barcelona nos han comentado que existen: «Muchos problemas. Tenemos unas normas y la escuela nos obliga a coger otras. Hay cosas que la escuela nos obliga a pasar. Por ejemplo, la mujer musulmana no tiene que ir desnuda en público, por ejemplo en la piscina con los hombres. Eso es un problema. Luego al practicar gimnasia, nosotros tenemos peleas con esto, hay deporte que debe tener contacto con otro y no debe haber, no debe haber provocación. En la escuela enseñáis a que chica ande con el chico y las consecuencias las pagamos entre todos. En la escuela ponemos el musulmán. Por ejemplo, en la escuela se pone en medio un musulmán con una niña que es de aquí, con el tiempo se forman parejas y eso no irá bien con el tiempo porque son diferentes. Enseñan a dejar a ser musulmán y luego debe volver a serlo (...) Enseñan cómo practicar el sexo, enseñan a un niño de ocho o diez años, esto no lo veo bien».

${ }^{32}$ Aunque en las escuelas cada vez se tiene más en cuenta, aún existen situaciones como la que describe nuestro interlocutor de una mezquita de Girona: «Gobierno debe dar una facilidad, tiene que ayudar algo. Los directores tienen que dar una facilidad: no dar cerdo, no obligar a quitarse el pañuelo, no hacer gimnasia algunas chicas... Yo he ido varias veces a pedirlo a una escuela de Barcelona y me decían que no había problema, pero hasta que fui a ver al director se lo hacían comer. Decía la cocinera que no hiciera caso de esas tonterías. No creen que sea importante para nosotros, y es muy importante. Los del colegio tendrían que vigilar más. (...) Gobierno tiene que regularlo, explicarlo a los periódicos, a la televisión. Además, podrían pagar maestros que enseñen lengua y religión».

${ }^{33}$ Muy representativo resulta el discurso obtenido en una entrevista en Barcelona: «Hay un padre que sufre porque él ya se le van (los hijos) y se pregunta por qué he venido aquí. El padre es el responsable y debemos salvarles. No es necesario hablarles de España, de la cultura de España, ya lo aprenden en la calle, ya tienen tiempo. Nosotros tenemos que enseñarles su origen: Islam, cultura, lengua...; padres deben hacerlo. Aquí está el problema, el padre se levanta a las seis y media para ir a trabajar, vuelve a la una y otra vez al trabajo. Y por la noche pocas ganas tiene. (...) La mayoría del tiempo los niños en el colegio, son muchas horas. El niño en casa aprende pocas cosas: trae esto, dame eso... pero les falta un aprendizaje a fondo. Por ejemplo la gramática. El niño
} 
lengua y religión, al menos donde el número de alumnos musulmanes sea elevado, como la ley indica (resulta interesante consultar el Real Decreto 2438/1994, de 16 de diciembre y la Orden por la que se dispone la publicación de los curriculum de la enseñanza de la religión islámica BOE 18 de enero de 1996) y se amparan que Cataluña tiene una tradición de continua reivindicación de la lengua propia y discurso de respeto a la diversidad lingüística.

Esto no quiere decir que los padres se desentiendan del papel que les toca (limitado por fuerza ajena por los horarios laborales), como tampoco lo pretenden las asociaciones y mezquitas; lo que sucede es que no se explican por qué la escuela no observa seriamente su diferencia ${ }^{34}$. Las mezquitas asumen, o tienen intención de asumir, la enseñanza de la lengua y de la religión impartiendo sus propias clases ${ }^{35}$. Pero no siempre disponen de un local adecuado ni pueden contratar un profesor preparado. Así que la solicitud que llevan a la escuela demandando mayor consideración respecto a sus propias necesidades se convierte en una de sus principales reivindicaciones, porque en la mayoría de casos no lo hace ${ }^{36}$.

sabe hablar, pero no sabe gramática. Hace falta más tiempo. Se queda con el mínimo. Se debe montar un sitio para enseñar a la gente. No hace falta enseñarles el catalán y castellano, los niños lo saben, incluso mejor que los padres. Cuando llega una carta muchos la pasan al hijo para que la lea, a lo mejor los padres no lo saben. El crío está aprendiendo más el catalán y el español, y árabe no sabe. Cuando vamos de vacaciones a Marruecos le llama uno y no entiende».

${ }^{34}$ En una mezquita creada en 1991 en Barcelona se nos decía lo siguiente: «Este país es cristiano, viven más tiempo en el colegio que con los padres. Entonces, cuando salen del colegio van a jugar con los hijos de los cristianos. La mayoría del tiempo están ocupados, entonces no enseñan como nuestros padres. Se acostumbran con cristianos, al idioma, las costumbres... (...) Mejor en clase una hora de árabe o hablar de la religión, pero como no quieren o no tienen pensamiento de hacerlo, las cosas van así».

${ }^{35}$ Un fragmento de entrevista realizada en Girona sirve de ejemplo del discurso más general: «Aquí, en las escuelas, nada más castellano y catalán. Los niños deben saber un poco de árabe, de religión, el Corán. Un chico se pierde, la escuela está hecha para los españoles, les hacen españoles. (...) En el colegio castellano y catalán, en casa les intentamos enseñar nuestra lengua, pero en casa pasan cinco minutos, con el crío un tiempo pero no es suficiente, y en el colegio ocho horas. Van aprendiendo más el catalán que el castellano que el árabe. Por eso queremos crear un centro. Para nosotros mejora nuestro Islam y los críos den clases en árabe, aprendan el árabe. Que el día de mañana, que vayan a su tierra de vacaciones, por ejemplo, ella se siente. Con la gente de allí puedan hablar, no pueden hablar español entonces ese niño se siente un poco marginado, se siente solo. Esto es más por los críos que por nosotros».

${ }^{36}$ «Como escuela va bien. Pero un punto crítico, que ahora hemos conseguido, es enseñar el idioma y el Islam. Porque antes, si no querías que le enseñaran religión cristiana no había manera. Ahora, en algunas partes lo hemos conseguido, pero no en todos los lugares. Si juntas en una clase diez niños del mismo bando la escuela está obligada a poner un profesor que le enseñe la lengua del país de origen y la religión que ellos quieran. Es un poco difícil, pero se intenta hacer» (Imán de una mezquita de Barcelona fundada en 1993). 


\section{CONCLUSIONES}

Los flujos migratorios de los últimos treinta años, especialmente de los últimos veinte, han comportado el incremento de la heterogeneidad cultural y también religiosa en España y en Cataluña. A la diversidad existente se han ido sumando, y cada vez será más evidente esta presencia, personas procedentes de otros países que nos resultan desconocidos y hasta exóticos. Pero, en general, aún no se ha dedicado especial atención desde la sociología a estos «nuevos musulmanes», más allá de su estudio como inmigrantes extracomunitarios, perspectiva más habitual. Por este motivo, nos planteamos analizar el Islam en Cataluña a partir de la dinámica seguida por las mezquitas, utilizando una metodología cualitativa, es decir, entrevistando a imanes o representantes de las mezquitas que funcionan en las diferentes comarcas catalanas.

Considerando que el inmigrante es portador de una cultura, una creencia religiosa, que no siempre encaja ni tiene por qué encontrarse cómodo en la sociedad de recepción, insistimos en conocer hasta qué punto están dispuestos a adaptarse (léase asimilarse) y cómo viven este proceso. Lo primero que se debe recordar de lo expuesto anteriormente es que son conscientes de que en una sociedad de mayoría no musulmana deben adaptar y flexibilizar su comportamiento religioso, dando énfasis a la armonización o articulación, pero no a la renuncia. En estas condiciones, el asentamiento de inmigrantes musulmanes (cuyo indicador es la propia creación de mezquitas) procedentes principalmente de África, sobre todo del norte, les lleva a movilizarse y organizarse para mantener la continuidad de sus creencias y la práctica que conlleva. Hoy por hoy, la introducción de la práctica religiosa musulmana se encuentra en una fase evolutiva en que se dan diferentes transacciones (privadas y públicas) que tienen su base en dos pilares fundamentales que condicionan el proceso de integración: la traducción de las referencias sociales y la integración de las instituciones islámicas. La dinámica que se ha ido siguiendo en este proceso, y los condicionantes aportados por ambos lados, llevará a situaciones diferentes, como ha sucedido en Gran Bretaña, Alemania, Bélgica y Francia.

La evolución de esta presencia en España se ha desarrollado considerablemente durante los años noventa, y a nuestro parecer lo hará aún más en los próximos. Este hecho comporta que situaciones que anteriormente no eran percibidas como conflictivas o, al menos, que no se consideraban de urgente resolución (ya que estas comunidades no reivindicaban su reconocimiento y aceptación a nivel social y cultural) están pasando a un primer plano del debate sobre el multiculturalismo y las relaciones interculturales.

Nuestro trabajo, además de aportar datos descriptivos, hasta este momento inexistentes, sobre el número y la ubicación de las mezquitas presentes en toda la geografía catalana, nos ha permitido profundizar en los motivos por los cuales se plantearon la necesidad de crear esos centros de culto y reunión, cómo lo logra- 
ron, qué situaciones son las que más les preocupan, cómo creen que debe encararse el futuro... así como describir, superficialmente, las relaciones que mantienen entre los diferentes imanes.

Parece, según todo lo anterior, que a pesar de que la legislación permite materializar algunas de sus reivindicaciones, ésta no acaba por desplegarse aunque sea con todas las limitaciones que tiene. Todo lo que se solicita gira en torno al reconocimiento, pero también a evitar la pérdida de la cultura (en nuestro trabajo la hemos focalizado en la religión y en la lengua), de su presencia y obtención de unos derechos que creen tener y que para muchos la legislación les reconoce. Así pues, una articulación no problemática para ninguna de las partes parece ser lo más adecuado. La sociedad y la escuela laicas, pero con un importante bagaje católico, deben aceptar la necesidad de adecuarse, y a su vez los inmigrantes también deben estar dispuestos a hacerlo, a una diversidad cultural y religiosa que cada vez debe ser más tenida en consideración. Creemos, como queda dicho, que los años noventa y el primer decenio del nuevo milenio representará, sin ninguna duda, un periodo de ajuste entre culturas, durante el cual será necesario articular, por ambas partes, los intercambios que se establezcan. En este proceso jugarán un papel destacado las mezquitas que existen y las que se vayan creando, especialmente las que se están convirtiendo a pasos agigantados en un referente de las otras. Y en este sentido, podría llegar a existir en Cataluña una cabeza única si finalmente se construye una gran mezquita en Barcelona.

\section{BIBLIOGRAFÍA}

CRESPO, R. (1997), «Inmigración y escuela», en VVAA, II Informe sobre inmigración y trabajo social, pp. 625-663, Barcelona, Diputación de Barcelona.

DASSETTO, F. (1990a), «Pour une théorie des cycles migratoires», en Bastenier, A. y Dassetto, F. (eds.), Immigrations et nouveaux pluralismes. Une confrontation de sociétés, pp. 11-39, París, De Boeck Université.

(1990b), «Visibilisation de l'Islam dans l'espace public», en Bastenier, A. y Dassetto, F. (eds.), Immigrations et nouveaux pluralismes. Une confrontation de sociétés, pp. 179-208, Parí, De Boeck Université

(1990c), «Politique d'intégration et Islam en Belgique», Revue Européenne des Migrations Internationales, Volume 6- $\mathrm{n}^{\circ}$ 2, pp. 107-122.

GARRETA, J. (1998), La integració sociocultural de les minories ètniques. Estudi comparatiu entre inmigrants extracomunitaris residents a les províncies de Lleida i Osca, Bellaterra, Universitat Autònoma de Barcelona (formato microficha).

(1998a), "Minorías étnicas, asociacionismo e integración sociocultural", Revista Papers de Sociología, $\mathrm{n}^{\circ}$ 56, pp. 117-150. 
(1999), «Les relacions interpersonals i familiars en el procés d'integració social», Perspectiva social, $\mathrm{n}^{\circ} 41$, pp. $37-60$.

(1999a), Los menores de las minorías étnicas en los Centros de Acogida de Cataluña: vidas y experiencias (Documento no publicado y que está en el fondo de Serveis de Cultura Popular del Grupo FUS en Barcelona).

KASTORYANO, R. (1994), «Construction de communautés et négociation des identités: les migrants musulmans en France et en Allemagne», en Martín, D.C., Cartes d'identité. Comment dit-on «nous» en politique?, pp. 229-244, París, Presses de la Fondation Nationale des Sciences Politiques.

KEPEL, G. (1991a), Les banlieues de l'Islam. Naissance d'une religion en France, París, Éditions du Seuil.

(1991b), La revanche de Dieu, París, Éditions du Seuil.

(1995a), «Entre sociedad y comunidad: los musulmanes en el Reino Unido y en Francia hoy», en Abumalham, M., Comunidades islámicas en Europa, pp. 319-336, Madrid, Trotta.

(1995b), Al Oeste de Alá. La penetración del Islam en Occidente, Barcelona, Paidós Ibérica (Primera edición 1994: À l'Ouest d'Allah, París, Seuil).

LEVEAU, R. (1994), «Éléments de réflexion sur l'Islam en Europe», Revue Européenne des Migrations Internationales, Volume 10, $\mathrm{n}^{\circ} 1, \mathrm{pp}$. 157-168.

LEVEAU, R. y G. KEPEL (1988) (dir.), Les musulmans dans la société française, París, Presses de la Fondation Nationale des Sciences Politiques.

LÓPEZ, B. y N. OLMO (1995), «Islam e inmigración», en Abumalham, M., Comunidades islámicas en Europa, Madrid, Trotta, pp. 257-276.

LOSADA CAMPOS, T. (1995), «Inmigración musulmana: retos humanos, culturales y religiosos», en Abumalham, M., Comunidades islámicas en Europa, Madrid, Trotta, pp. 189-199.

MORERAS, J. (1996), «Musulmans a Barcelona: espais i dinàmiques comunitàries», Revista Barcelona Societat, $\mathrm{n}^{\mathrm{a}}$ 6, pp. 85-91.

(1999), Musulmanes en Barcelona. Espacios y dinámicas comunitarias, Barcelona, CIDOB edicions.

ROZENBERG, D. (1996), «Minorías religiosas y construcción democrática en España», Revista Española de Investigaciones Sociológicas, $\mathrm{n}^{\circ} 74$, pp. 245-265.

TATARY, R. (1995), «Libertad religiosa y acuerdo de cooperación del Estado Español con la Comisión Islámica de España», en Abumalham, M. Comunidades islámicas en Europa, pp. 165-172, Madrid, Trotta. 
SUMMARY. The migrations of the last thirty years, and especially of the last twenty, have carried an increment of the cultural and religious heterogeneousness in Spain, and particularly in Catalonia. In the analysis of the cultural diversity, it's necessary to bear in mind the religious matter. For this reason, observing the crescent number of Muslims, the research and this article portray the Islam presence in Catalonia to make use of imam's personal interviews. This article presents Catalonian mosques, the dynamic and the motivations for their creation, the difficulties and the social problems they found, as well as the future threats that mosques and Catalonia have to face.

E-mail: jgarreta@geosoc.udl.es 